\title{
Pancreatic and gut hormones as predictors of new-onset prediabetes after non-necrotising acute pancreatitis: a prospective longitudinal cohort study
}

\author{
Sakina H Bharmal, Wandia Kimita, Juyeon Ko and Maxim S Petrov \\ School of Medicine, University of Auckland, Auckland, New Zealand
}

Correspondence should be addressed to S H Bharmal or M S Petrov: s.bharmal@auckland.ac.nz or m.petrov@auckland.ac.nz

\begin{abstract}
Objective: Early identification of individuals at high risk for metabolic derangements after an attack of acute pancreatitis (AP) is critical with a view to tertiary preventing of this disease. The aim was to investigate whether fasting pancreatic and gut hormones at baseline were predictive of future risk of new-onset prediabetes after acute pancreatitis (NOPAP) in individuals with non-necrotising AP.

Methods: This was a prospective longitudinal cohort study that included 69 consecutive non-diabetic participants with AP, of whom $55 \%(n=38)$ had normoglycaemia both at baseline and during follow-up, 25\% $(n=17)$ had prediabetes both at baseline and during follow-up, and $20 \%(n=14)$ were normoglycaemic at baseline but developed NOPAP during follow-up. The associations between the study groups and circulating fasting levels of pancreatic and gut hormones (insulin, glucagon, C-peptide, amylin, glucose-dependent insulinotropic peptide, glucagon-like peptide-1, pancreatic polypeptide, and peptide YY) were studied using multinomial regression in both unadjusted and adjusted analyses. Results: Elevated plasma insulin and glucagon at baseline were significantly associated with NOPAP (adjusted odds ratio $1.99,95 \% \mathrm{Cl} 1.01$ to 3.92 and adjusted odds ratio 3.44, $95 \% \mathrm{Cl} 1.06$ to 11.19 , respectively). The same hormones had no significant association with antecedent prediabetes in AP. The other studied hormones were not significantly associated with the study groups. Conclusions: Normoglycaemic AP individuals with elevated fasting levels of insulin and glucagon at baseline constitute a high-risk group for future NOPAP.
\end{abstract}

\author{
Key Words \\ - pancreatitis \\ - insulin \\ - glucagon \\ - new-onset prediabetes \\ - prediction \\ - prospective cohort study
}

\section{Introduction}

Post-pancreatitis diabetes mellitus, the largest contributor to diabetes of the exocrine pancreas (1), is the second most common type of adult-onset diabetes (2). Post-pancreatitis diabetes mellitus is associated with a higher risk of allcause mortality and hospitalisation (for gastrointestinal and infectious diseases-related complications) than type 2 diabetes (3), putting a considerable burden on healthcare resources. Post-pancreatitis diabetes is a frequent sequela of acute pancreatitis (AP). A projection study estimated the annual incidence for post-pancreatitis diabetes mellitus in AP individuals to increase from 5.2 per 100,000 persons in 2020 to 13.6 per 100,000 persons by 2050 (4). Further, aggregated evidence from several studies suggests that individuals with $\mathrm{AP}$ are at a two-times increased risk of new-onset diabetes than the general population, independent of the severity of $\operatorname{AP}(5,6,7)$. Given that the cumulative incidence of new- 
onset diabetes increases with time (8), there is a need for early identification of high-risk individuals to introduce targeted strategies for preventing and managing this sequela of AP.

Prediabetes is one of the most prominent risk factors for new-onset diabetes mellitus (9). It is estimated that up to $75 \%$ of individuals with prediabetes may progress to diabetes mellitus $(10,11)$. Data from several diabetes prevention trials suggest the benefits of screening for prediabetes for timely and effective prevention of diabetes mellitus $(12,13,14,15)$. Ideally, a blanket mass surveillance of all AP patients at regular intervals would ensure early detection of individuals at a substantial risk of developing glucose abnormalities. However, AP is the most common disease of the exocrine pancreas, with the annual incidence of 34 cases per 100,000 persons worldwide (16). Therefore, an indiscriminate surveillance is unlikely to be practical and cost-effective. This brings to the fore the importance of identifying predictors that enable accurate identification of high-risk individuals shortly after AP diagnosis with the ultimate goal of targeted surveillance. Our longitudinal prospective cohort as part of the LACERTA project includes prospectively diagnosed individuals with AP who were followed up after hospital discharge at regular intervals for up to 2 years (8). This prospective longitudinal cohort provides a unique framework for the investigation of blood biomarkers at baseline that could distinguish individuals who subsequently develop NOPAP from those who remain normoglycaemic after AP. The DORADO project (a crosssectional study of individuals with a history of AP), which preceded and did not overlap with the LACERTA project, sieved more than 50 blood biomarkers and identified a number of pancreatic and gut hormones that play a role in derangements of glucose homeostasis after an attack of AP (17). Because derangements of glucose homeostasis after necrotising pancreatitis are typically a function of the extent of pancreatic necrosis (and, hence, relatively straightforward to predict), the current challenge is to predict derangements of glucose homeostasis after non-necrotising AP.

The aim was to investigate whether fasting levels of pancreatic and gut hormones measured at baseline can predict future risk of NOPAP in individuals with nonnecrotising AP.

\section{Methods}

\section{Study design}

This prospective longitudinal cohort study was part of the LACERTA project. The study conformed to the ethical guidelines of the 1975 Declaration of Helsinki as reflected in a priori approval by the Health and Disability Ethics Committee (approval number 13/STH/182). The study included adults with non-necrotising AP admitted to Auckland City Hospital (New Zealand) who were followed up over a period of 24 months after hospital discharge. Blood samples collected at baseline (mean 0.9 months, from the date of hospitalisation for $\mathrm{AP}$ ) and during follow-up were used in the present study.

\section{Study cohort}

Individuals who had a primary diagnosis of nonnecrotising AP (determined based on the absence of pancreatic necrosis on CT during hospitalisation), were at least 18 years of age, and provided informed consent were included in the study.

Individuals who had diabetes mellitus (defined as glycated haemoglobin (HbA1c) $\geq 48 \mathrm{mmol} / \mathrm{mol}(6.5 \%)$ (18) and/or taking antidiabetic medications), chronic pancreatitis, intra-operative diagnosis of pancreatitis, post-endoscopic retrograde cholangiopancreatography pancreatitis, malignancy, cognitive disability, or were pregnant at the time of hospitalisation for AP or during follow-up were excluded from the study.

\section{Study groups}

Individuals were categorised into three study groups based on their fasting plasma glucose (FPG) and HbA1c measurements at both baseline and during follow-up.

(i) Normoglycaemia after AP (NAP): individuals with $\mathrm{HbA} 1 \mathrm{c}<39 \mathrm{mmol} / \mathrm{mol}$ at baseline, and FPG $<5.6$ $\mathrm{mmol} / \mathrm{L}(100 \mathrm{mg} / \mathrm{dL})$ and $\mathrm{HbA} 1 \mathrm{c}<39 \mathrm{mmol} / \mathrm{mol}$ (5.7\%) during follow-up were deemed to have NAP.

(ii) Antecedent prediabetes before AP (APAP): individuals with $\mathrm{HbA1c}$ between 39 and $47 \mathrm{mmol} / \mathrm{mol}$ at baseline, and FPG between 5.6 and $6.9 \mathrm{mmol} / \mathrm{L}(100-125 \mathrm{mg} /$ dL) and/or HbA1c between 39 and $47 \mathrm{mmol} / \mathrm{mol}$ (5.7$6.4 \%$ ) during follow-up were deemed to have APAP.

(iii) New-onset prediabetes after AP (NOPAP): individuals with $\mathrm{HbA} 1 \mathrm{c}<39 \mathrm{mmol} / \mathrm{mol}$ at baseline, and FPG between 5.6 and $6.9 \mathrm{mmol} / \mathrm{L}(100-125 \mathrm{mg} / \mathrm{dL})$ and/ or HbA1c between 39 and $47 \mathrm{mmol} / \mathrm{mol}$ (5.7-6.4\%) during follow-up were deemed to have NOPAP.

The used thresholds were in line with the DEP criteria (19). Given that FPG $>5.6 \mathrm{mmol} / \mathrm{L}(100 \mathrm{mg} / \mathrm{dL})$ at baseline might be due to stress hyperglycaemia (20), FPG at baseline was not taken into consideration in grouping the study participants.

This work is licensed under a Creative Commons Attribution-NonCommercial-NoDerivatives 4.0 enternational License ifica com at $04 / 26 / 2023 \quad 05: 12: 14 \mathrm{Am}$ 


\section{Laboratory measurements}

Fasting venous blood samples were collected after an overnight fast ( $\geq 8 \mathrm{~h}$ ) both at baseline and during follow-up. Glycated haemoglobin and FPG were measured on whole never-frozen blood immediately after blood collection. Glycated haemoglobin was measured using boronate affinity chromatography assay (Trinity Biotech, County Wicklow, Ireland) and FPG was measured using enzymatic colourimetric assay (F. Hoffmann-La Roche, Basel, Switzerland). The other collected tubes of blood were centrifuged at $4000 \boldsymbol{g}$ for $5.5 \mathrm{~min}$ at $4^{\circ} \mathrm{C}$, plasma separated, aliquoted, and stored at $-80^{\circ} \mathrm{C}$ for future analyses. Amylin, C-peptide, glucagon, glucose-dependent insulinotropic peptide (GIP), glucagon-like peptide-1 (GLP-1), insulin, pancreatic polypeptide, and peptide YY were measured in plasma samples using the MILLIPLEX ${ }^{\bullet}$ MAP human metabolic hormone magnetic bead panel. Protease (Merck KGaA) and DPP-IV inhibitors (Merck KGaA) were added to the samples. All assays were conducted as per the user's manual. Results were quantified using the Belysa ${ }^{\mathrm{TM}}$ immunoassay curve fitting software (Merck KGaA).

\section{Definitions of covariates}

Sex was a binary variable and categorised into 'men' and 'women'. Age at baseline was categorised (based on interquartile range (IQR)) into 'young adults' $(\leq 25$ th percentile: $\leq 36$ years), 'middle-aged adults' (25th-75th percentile: 37-64 years), and 'older adults' ( $\geq$ 75th percentile: $\geq 65$ years). BMI $\left(\mathrm{kg} / \mathrm{m}^{2}\right)$ was determined using a stadiometer. BMI was categorised into normal $\leq 25 \mathrm{~kg} / \mathrm{m}^{2}$ and overweight/obese $>25 \mathrm{~kg} / \mathrm{m}^{2}$. Smoking was a binary variable. The smoking status was categorised as 'yes' for individuals who were current smokers at the time of baseline blood collection and as 'no' for other individuals. Aetiology was categorised into biliary, alcohol-related, and other. Recurrence was a binary variable and was deemed to be present if individuals had one or more episodes of AP (at least 30 days apart) prior to their participation in the present study. Cholecystectomy was a binary variable and was deemed to be present if participants underwent cholecystectomy within 3 months of baseline blood collection.

\section{Statistical analyses}

All statistical analyses were done using SPSS 27.0. For all analyses, $P$ values $<0.05$ were deemed statistically significant. Baseline characteristics of individuals in the study groups were presented as frequency or median (IQR). Differences in baseline characteristics between individuals in the three groups were compared using Fisher's exact tests or one-way ANOVA. The assumption of normality for ANOVA was not met and, therefore, the pancreatic and gut hormones variables were log-transformed. Other statistical analyses were conducted in the following steps.

First, multinomial logistic regression analyses were used to investigate the associations between the APAP and NOPAP groups and pancreatic and gut hormones in both unadjusted (i.e. model 1) and adjusted (i.e. model 2) models. For all the analyses, the NAP group was used as the reference. The analyses were adjusted for age, sex, BMI, and aetiology. Data were presented as odds ratio (OR) with corresponding 95\% CI and $P$ values.

Second, receiver-operating characteristic (ROC) curves were generated from univariate analyses comparing NOPAP with NAP. The area under the curve (AUC) was calculated to quantify the discriminatory power of pancreatic and gut hormones in predicting NOPAP (21). Cut-off thresholds, predictive values, and likelihood ratios were derived for each hormone $(22,23)$.

Third, backward regression analyses were used to investigate the effects of several patients- and pancreatitisrelated characteristics (age, sex, BMI, smoking, aetiology, recurrence, and cholecystectomy) on the studied hormones, separately in the three groups. Each hormone was analysed individually as a continuous dependent variable and age, sex, BMI, smoking, aetiology, recurrence, and cholecystectomy as independent variables. Data for statistically significant covariates were presented as B coefficients with corresponding 95\% CI, $P$ values, and adjusted $R^{2}$ values.

\section{Results}

\section{Characteristics of participants}

The study included a total of 69 individuals, of whom $55 \%$ $(n=38)$ had NAP, 25\% $(n=17)$ had APAP, and 20\% $(n=14)$ developed NOPAP during follow-up. The mean (S.E.M.) time to diagnosis of NOPAP was 6 (2) months from baseline blood collection. Other baseline characteristics of study participants are presented in Table 1.

\section{Pancreatic and gut hormones in the study groups}

The median (IQR) for insulin was $91.08 \mathrm{pmol} / \mathrm{L}$ (45.40, 170.71) in the NAP group, $127.74 \mathrm{pmol} / \mathrm{L}(65.22,391.42)$ 
in the APAP group, and $202.60 \mathrm{pmol} / \mathrm{L}(85.54,344.63)$ in the NOPAP group $(P=0.099)$. Insulin was not significantly associated with NOPAP in the unadjusted model but was significantly associated with NOPAP in the adjusted model. Insulin increased the odds of developing NOPAP by an OR $(95 \% \mathrm{CI})$ of $1.99(1.01,3.92)(P=0.046)$ in the adjusted model (Table 2). Insulin was not significantly associated with APAP in either the unadjusted or the adjusted models (Table 2). The median (IQR) for glucagon was $14.32 \mathrm{ng} / \mathrm{L}(11.61,23.61)$ in the NAP group, 22.43 $\mathrm{ng} / \mathrm{L}(10.18,24.31)$ in the APAP group, and $20.44 \mathrm{ng} / \mathrm{L}$ $(15.29,31.31)$ in the NOPAP group $(P=0.136)$. Glucagon was not significantly associated with NOPAP in the unadjusted model but was significantly associated with NOPAP in the adjusted model. Glucagon increased the odds of developing NOPAP by an OR (95\% CI) of 3.44 $(1.06,11.19)(P=0.040)$ in the adjusted model (Table 2$)$. Glucagon was not significantly associated with APAP in the unadjusted and adjusted models (Table 2). The median (IQR) for amylin was $2.88 \mathrm{pmol} / \mathrm{L}(2.62,3.14)$ in the NAP group, $3.14 \mathrm{pmol} / \mathrm{L}(1.96,3.49)$ in the APAP group, and $2.81 \mathrm{pmol} / \mathrm{L}(1.89,3.14)$ in the NOPAP group $(P=0.719)$. Amylin was not significantly associated with

Table 1 Characteristics of the study groups.

\begin{tabular}{|c|c|c|c|c|}
\hline \multirow[b]{2}{*}{ Characteristic } & \multicolumn{3}{|c|}{ Group } & \multirow[b]{2}{*}{$p$} \\
\hline & NAP & APAP & NOPAP & \\
\hline Age, $n$ & & & & 0.739 \\
\hline Young adults & 11 & 4 & 3 & \\
\hline Middle-aged adults & 20 & 8 & 6 & \\
\hline Older adults & 7 & 5 & 5 & \\
\hline Sex, $n$ & & & & 0.948 \\
\hline Men & 17 & 8 & 7 & \\
\hline Women & 21 & 9 & 7 & \\
\hline $\mathrm{BMI}, n$ & & & & 0.390 \\
\hline Normal & 14 & 3 & 5 & \\
\hline Overweight/obese & 24 & 14 & 9 & \\
\hline Aetiology, $n$ & & & & 0.382 \\
\hline Biliary & 21 & 9 & 8 & \\
\hline Alcohol-related & 6 & 1 & 4 & \\
\hline Other & 11 & 7 & 2 & \\
\hline Recurrence, $n$ & & & & 0.925 \\
\hline No & 29 & 14 & 11 & \\
\hline Yes & 9 & 3 & 3 & \\
\hline Cholecystectomy, $n$ & & & & 0.285 \\
\hline No & 20 & 12 & 6 & \\
\hline Yes & 18 & 5 & 8 & \\
\hline Smoking, $n$ & & & & 0.425 \\
\hline No & 25 & 12 & 8 & \\
\hline Yes & 8 & 5 & 6 & \\
\hline
\end{tabular}

The age categories were as follows: young adults $\leq 36$ years, middle-aged adults 37-64 years, older adults $\geq 65$ years. The body composition categories were as follows: normal BMI $\leq 25 \mathrm{~kg} / \mathrm{m}^{2}$, overweight/obese $\mathrm{BMI}>25 \mathrm{~kg} / \mathrm{m}^{2}$

https://ec.bioscientifica.com https://doi.org/10.1530/EC-21-0229

2021 The authors Published by Bioscientifica Ltd either NOPAP or APAP in the unadjusted and adjusted models (Table 2). The median (IQR) for C-peptide was $0.26 \mathrm{nmol} / \mathrm{L}(0.13,0.49)$ in the NAP group, $0.24 \mathrm{nmol} / \mathrm{L}$ $(0.13,0.44)$ in the APAP group, and $0.39 \mathrm{nmol} / \mathrm{L}(0.25$, $0.58)$ in the NOPAP group $(P=0.329)$. C-peptide was not significantly associated with either NOPAP or APAP in the unadjusted and adjusted models (Table 2). The median (IQR) for GIP was $7.85 \mathrm{pmol} / \mathrm{L}(3.06,15.84)$ in the NAP group, $10.16 \mathrm{pmol} / \mathrm{L}(4.07,19.27)$ in the APAP group, and $8.32 \mathrm{pmol} / \mathrm{L}(6.76,22.86)$ in the NOPAP group $(P=0.335)$. The glucose-dependent insulinotropic peptide was not significantly associated with either NOPAP or APAP in the unadjusted and adjusted models (Table 2). The median (IQR) for GLP-1 was $41.56 \mathrm{pmol} / \mathrm{L}(25.03,57.43)$ in the NAP group, $40.97 \mathrm{pmol} / \mathrm{L}(26.10,69.53)$ in the APAP group, and $37.60 \mathrm{pmol} / \mathrm{L}(19.75,53.08)$ in the NOPAP group $(P=0.789)$. Glucagon-like peptide-1 was not significantly associated with either NOPAP or APAP in the unadjusted and adjusted models (Table 2). The median (IQR) for pancreatic polypeptide was $11.61 \mathrm{pmol} / \mathrm{L}$ (6.34, $21.81)$ in the NAP group, $18.75 \mathrm{pmol} / \mathrm{L}(9.38,37.72)$ in the APAP group, and $21.51 \mathrm{pmol} / \mathrm{L}(11.25,39.20)$ in the NOPAP group $(P=0.197)$. The pancreatic polypeptide was not significantly associated with either NOPAP or APAP in the unadjusted and adjusted models (Table 2). The median (IQR) for peptide YY was $8.40 \mathrm{pmol} / \mathrm{L}(4.32,10.60)$ in the NAP group, $9.95 \mathrm{pmol} / \mathrm{L}(4.32,15.15)$ in the APAP group, and $9.95 \mathrm{pmol} / \mathrm{L}(8.40,15.66)$ in the NOPAP group $(P$ $=0.170)$. Peptide YY was not significantly associated with either NOPAP or APAP in the unadjusted and adjusted models (Table 2).

\section{Predictive accuracy of pancreatic and gut hormones}

The ROC curves for all the pancreatic and gut hormones at baseline as predictors of NOPAP are presented in Fig. 1. Insulin and glucagon, but not the other studied hormones, yielded statistically significant AUC. Insulin and glucagon combined had an AUC (95\% CI) of 0.74 $(0.60,0.87), P=0.012$. The cut-off value of $175 \mathrm{pmol} / \mathrm{L}$ for insulin had a sensitivity of $57.1 \%$, a specificity of $76.9 \%$, a negative predictive value of $83.3 \%$, a negative likelihood ratio of 0.56 , a positive predictive value of $47.1 \%$, and a positive likelihood ratio of 2.47 . The cutoff value of $21.4 \mathrm{ng} / \mathrm{L}$ for glucagon had a sensitivity of $46.1 \%$, a specificity of $69.2 \%$, a negative predictive value of $79.4 \%$, a negative likelihood ratio of 0.78 , a positive predictive value of $33.3 \%$, and a positive likelihood ratio of a 1.50 .
This work is licensed under a Creative Commons Attribution-NonCommercial-NoDerivatives 4.0 elnternationab ficense.ifica com at 04/26/2023 05:12:14AM 
Table 2 Associations between the study groups and pancreatic and gut hormones.

\begin{tabular}{|c|c|c|c|c|c|c|c|c|c|c|}
\hline \multirow[b]{3}{*}{ Hormone } & \multirow[b]{3}{*}{ Model } & \multirow[b]{3}{*}{ NAP } & \multicolumn{4}{|c|}{ APAP } & \multicolumn{4}{|c|}{ NOPAP } \\
\hline & & & \multirow[b]{2}{*}{ OR } & \multicolumn{2}{|c|}{$95 \% \mathrm{Cl}$} & \multirow[b]{2}{*}{$p$} & \multirow[b]{2}{*}{ OR } & \multicolumn{2}{|c|}{$95 \% \mathrm{Cl}$} & \multirow[b]{2}{*}{$p$} \\
\hline & & & & Lower & Upper & & & Lower & Upper & \\
\hline \multirow[t]{2}{*}{ Insulin } & 1 & Reference & 1.62 & 0.91 & 2.86 & 0.099 & 1.72 & 0.94 & 3.15 & 0.078 \\
\hline & 2 & & 1.66 & 0.92 & 2.99 & 0.094 & 1.99 & 1.01 & 3.92 & 0.046 \\
\hline \multirow[t]{2}{*}{ C-peptide } & 1 & Reference & 1.21 & 0.77 & 1.90 & 0.409 & 1.48 & 0.84 & 2.63 & 0.175 \\
\hline & 2 & & 1.24 & 0.78 & 1.97 & 0.357 & 1.52 & 0.83 & 2.79 & 0.172 \\
\hline \multirow[t]{2}{*}{ Amylin } & 1 & Reference & 1.10 & 0.28 & 4.29 & 0.887 & 0.59 & 0.15 & 2.41 & 0.466 \\
\hline & 2 & & 0.75 & 0.17 & 3.37 & 0.711 & 0.43 & 0.08 & 2.21 & 0.310 \\
\hline \multirow[t]{2}{*}{ Glucagon } & 1 & Reference & 1.32 & 0.57 & 3.06 & 0.518 & 2.76 & 0.99 & 7.71 & 0.052 \\
\hline & 2 & & 1.28 & 0.53 & 3.09 & 0.575 & 3.44 & 1.06 & 11.19 & 0.040 \\
\hline \multirow[t]{2}{*}{ GIP } & 1 & Reference & 1.24 & 0.76 & 2.01 & 0.384 & 1.50 & 0.84 & 2.65 & 0.168 \\
\hline & 2 & & 1.25 & 0.74 & 2.08 & 0.402 & 1.82 & 0.89 & 3.72 & 0.101 \\
\hline \multirow[t]{2}{*}{ GLP-1 } & 1 & Reference & 1.16 & 0.42 & 3.19 & 0.771 & 0.76 & 0.27 & 2.12 & 0.597 \\
\hline & 2 & & 1.21 & 0.40 & 3.60 & 0.736 & 0.66 & 0.20 & 2.14 & 0.484 \\
\hline \multirow[t]{2}{*}{ PPY } & 1 & Reference & 1.45 & 0.77 & 2.71 & 0.248 & 1.82 & 0.89 & 3.73 & 0.100 \\
\hline & 2 & & 1.46 & 0.75 & 2.84 & 0.264 & 1.83 & 0.84 & 3.98 & 0.128 \\
\hline \multirow[t]{2}{*}{ PYY } & 1 & Reference & 1.36 & 0.69 & 2.71 & 0.377 & 2.37 & 0.90 & 6.24 & 0.081 \\
\hline & 2 & & 1.32 & 0.65 & 2.69 & 0.447 & 2.48 & 0.78 & 7.86 & 0.123 \\
\hline
\end{tabular}

Model 1: unadjusted; Model 2: adjusted for age, sex, BMI, and aetiology. Bold indicates statistical signficance, $P<0.05$.

GIP, glucose-dependent insulinotropic peptide; GLP-1, glucagon-like peptide-1; PPY, pancreatic polypeptide; PYY, peptide YY.

\section{Effects of covariates on pancreatic and gut hormones in the study groups}

Aetiology, sex, and smoking had a significant positive association with insulin, whereas BMI and recurrence had a negative association with insulin in the NOPAP group. Specifically, women, being overweight/obese, smokers, others aetiology, and recurrent episodes of AP collectively explained $65 \%$ of the variance in insulin levels (Table 3 ). Age had a significant positive association with glucagon in the NOPAP group. Specifically, young age explained $57 \%$ of the variance in glucagon levels (Table 3). Age and aetiology had a significant positive association with GIP in the NOPAP group. Specifically, old age and individuals with non-alcohol and non-biliary aetiology collectively explained $69 \%$ of the variance in GIP levels. Recurrence had a significant negative association with C-peptide in the NOPAP group. Specifically, recurrent episodes of AP explained $45 \%$ of the variance in C-peptide levels. None of the studied covariates had a statistically significant association with amylin, GLP1, pancreatic polypeptide, and peptide YY in the NOPAP group (Table 3). The associations between the covariates and pancreatic and gut hormones in the APAP and NAP groups are presented in Table 3.

\section{Discussion}

The present study was the first prospective longitudinal study to investigate the relationship between fasting levels of eight pancreatic and gut hormones at baseline and the progression from normoglycaemia to NOPAP during follow-up of individuals with non-necrotising AP. Elevated levels of fasting insulin and glucagon in normoglycaemic individuals at baseline were the strongest predictors of subsequent NOPAP. Specifically, insulin increased the odds of progressing to NOPAP by an OR of $1.99(P=0.046)$ and glucagon by an OR of $3.44(P=0.040)$, after adjustment for patient-related and pancreatitis-related factors. Further, insulin and glucagon combined showed a good predictive accuracy $(\mathrm{AUC}=0.74)$ in predicting individuals at a high risk of future NOPAP. Importantly, the study purposely included the APAP group (i.e. patients with AP and co-existing prediabetes at baseline) and showed that neither insulin nor glucagon was significantly associated with the APAP group.

The presence of hyperinsulinaemia during a state of normoglycaemia is an established risk factor for the development of abnormal glucose metabolism in the general population $(24,25,26,27,28,29)$. A populationbased study showed that high fasting levels of insulin ( $\geq 75$ th percentile group in that cohort) at baseline were associated with approximately two-times increased risk of progressing to incident prediabetes during nine years of follow-up (24). Another long-term population-based study conducted over a follow-up period of 24 years also showed that normoglycaemic individuals with fasting insulin levels in the topmost quintile $(\geq 176.4 \mathrm{pmol} / \mathrm{L}$ in that cohort) were two times more likely to develop prediabetes than individuals with lower insulin levels (25). While hyperinsulinaemia is well recognised as a

This work is licensed under a Creative Commons Attribution-NonCommercial-NoDerivatives 4.0 elnternational License.ifica, com at $04 / 26 / 2023 \quad 05: 12: 14 \mathrm{Am}$ 
A
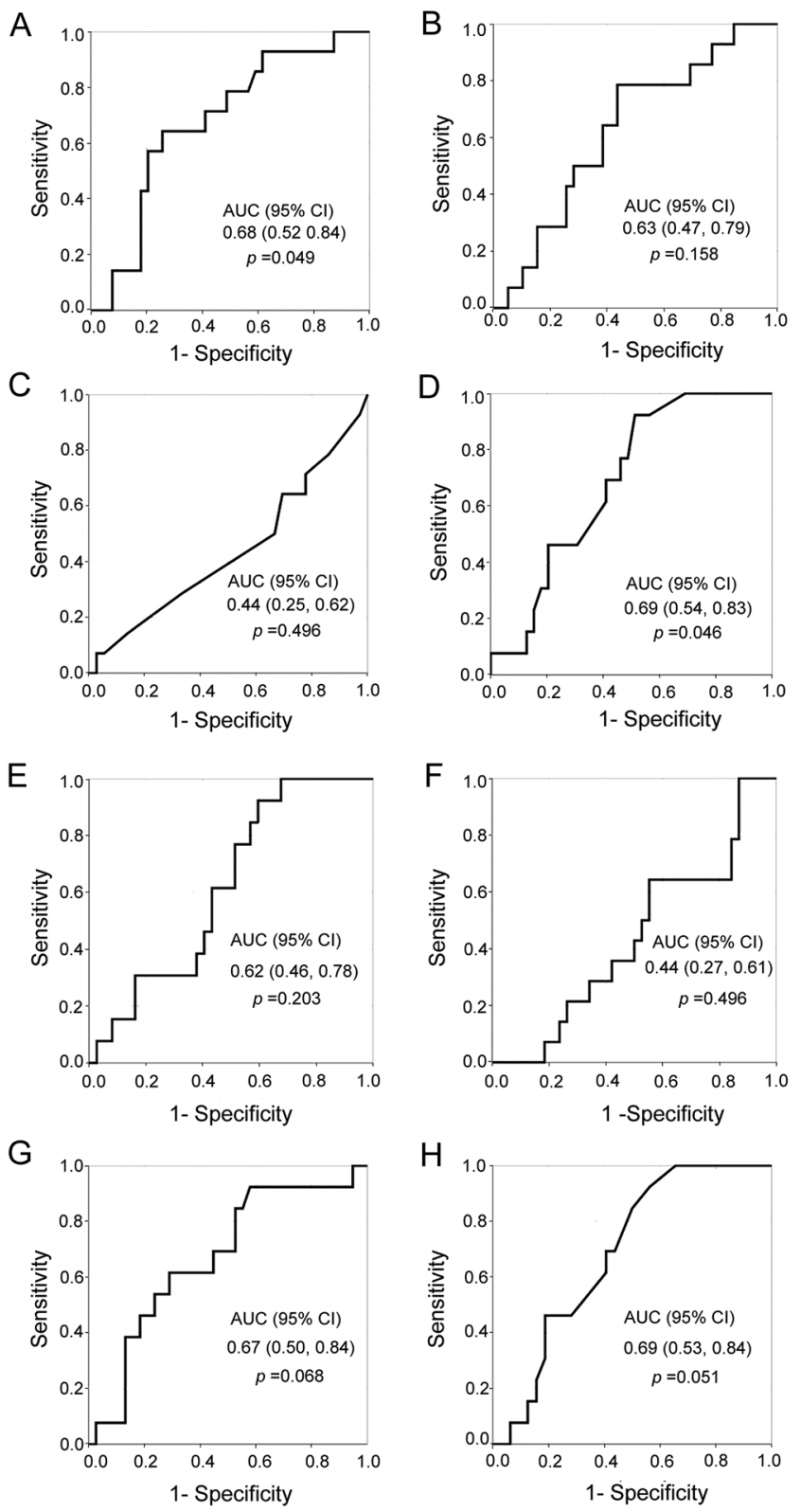

$\mathrm{H}$

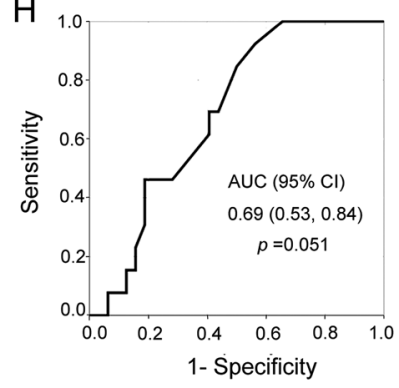

Figure 1

Receiver-operating characteristic curves of pancreatic and gut hormones for predicting new-onset prediabetes after acute pancreatitis at baseline (A) insulin; (B) C-peptide; (C) amylin; (D) glucagon; (E) glucose-dependent insulinotropic peptide; (F) glucagon-like peptide-1; (G) pancreatic polypeptide; (H) peptide YY. AUC, area under the curve. $262 \times 137 \mathrm{~mm}$.

predictor of incident prediabetes/type 2 diabetes, the relationship between hyperinsulinaemia and other types of diabetes (such as post-pancreatitis diabetes mellitus) is established to a lesser extent. Post-pancreatitis diabetes mellitus is less common than type 2 diabetes but has a considerably heavier burden than type 2 diabetes (30). Yet, there is a dearth of studies investigating biomarkers that could predict which patients with AP are at risk of post-pancreatitis diabetes mellitus. Earlier cross-sectional studies by the COSMOS group (the DORADO project) and others showed that increased insulin resistance and the resulting compensatory hyperinsulinaemia are some of the key mechanisms in the pathogenesis of post-acute pancreatitis diabetes mellitus $(31,32,33,34)$. In the present longitudinal cohort study, $20 \%$ of AP individuals with normoglycaemia who had elevated fasting insulin levels at baseline progressed to NOPAP during prospective follow-up. Further, baseline hyperinsulinaemia was associated with two-times increased risk of developing NOPAP after accounting for several covariates (such as age, sex, and BMI, and aetiology). These findings provide the strongest evidence to date implicating hyperinsulinaemia in the development of NOPAP. Our results suggest that elevated fasting insulin levels in normoglycaemic AP individuals can be considered as an early predictor of a high risk of future derangements of blood glucose metabolism in this setting. Given that the present study showed no significant association of C-peptide (a marker for insulin secretion) with NOPAP, the increase in insulin levels at baseline may not be due to increased insulin secretion but rather due to reduced insulin clearance. This and other possible mechanisms of hyperinsulinaemia (i.e. downregulation of insulin receptors, differences in $\beta$-cell size and mass, altered hypothalamic and parasympathetic signalling pathways) warrant investigations in purposely designed mechanistic studies $(31,35,36,37,38,39)$.

The other notable finding was that baseline fasting glucagon was significantly associated with progression from normoglycaemia to NOPAP during follow-up. An earlier cross-sectional study (as a part of the DORADO project) did not find a statistically significant association between fasting glucagon and post-pancreatitis diabetes mellitus $(40,41)$. Hence, the present longitudinal study takes the field further by demonstrating, for the first time, that elevated levels of fasting glucagon at baseline significantly increase the odds of developing NOPAP by more than three times (after accounting for patient-related and pancreatitisrelated characteristics). Earlier studies showed that fasting glucagon levels are higher in individuals with prediabetes (and type 2 diabetes) compared with individuals with normal glucose tolerance $(42,43,44)$, making it plausible that elevated baseline plasma glucagon in AP individuals represent an early pathogenic event prior to the onset of prediabetes. In the general population, elevated glucagon levels are typically attributed to impaired glucagoninsulin sensitivity relationship (42) or $\alpha$-cell compensatory changes (45). In patients with AP, elevated glucagon levels could relate to a stress-induced counter-regulatory and 
inflammatory response during acute illness (46). However, this would hold true for all AP patients, regardless of their prediabetes status. Moreover, the baseline blood samples were collected at a mean of 0.9 months after diagnosis of non-necrotising AP, suggesting that any transient inflammation-induced increase in glucagon would have resolved by the time of blood collection. Future studies will provide detailed mechanistic insights into the role of glucagon as an early predictor of NOPAP.

In the present study, we started to gain insights into the effect of several common covariates on circulating levels of glucagon and insulin (and the other studied hormones) in the post-acute pancreatitis setting. Young age (36 years or younger, based on the 25th percentile of the IQR) showed a significant association with glucagon in the NOPAP group, explaining $57 \%$ of the variance in glucagon levels. Several recent population-based studies showed that the age-specific risk of post-pancreatitis diabetes mellitus is the highest among young adults with AP $(6,47,48,49)$. A study from the UK showed that the risk of newly diagnosed diabetes in individuals aged 30-39 was significantly higher in those with a history of AP than in the general population without a history of AP $(\mathrm{OR}=1.68)(47)$. A study from Taiwan showed that the age-specific risk of postpancreatitis diabetes mellitus (irrespective of the severity of AP) was the highest in men aged $<45$ years (adjusted hazard ratio=7.46) (6). A study from Israel showed that AP individuals under the age of 40 years had the highest risk of developing diabetes (adjusted $\mathrm{OR}=4.65$ ) compared with the general population (48). Further, a study from New Zealand showed that young adults aged 30-34 with postpancreatitis diabetes mellitus had the greatest loss in life expectancy than young adults with other types of diabetes (49). The present study provides initial data that designate elevated levels of glucagon as a possible mechanistic basis for the higher burden of post-pancreatitis diabetes mellitus in young adults. However, given that the number of young adults in the NOPAP group was limited, the effect of age on glucagon in the context of metabolic derangements after pancreatitis warrants further investigations. Also, our study showed that $65 \%$ of the variance in insulin levels was explained by factors such as normal BMI $(\leq 25 \mathrm{~kg} /$ $\mathrm{m}^{2}$ ), sex (women), active tobacco smoking, first episode of AP, and non-biliary non-alcohol-related cause for AP. The above findings justify larger prospective studies into the independent effect of the above covariates on pancreatic hormones after an attack of AP.

Overall, our findings suggest that elevated insulin and glucagon levels could be reasonably accurate predictors of NOPAP among normoglycaemic people after an attack

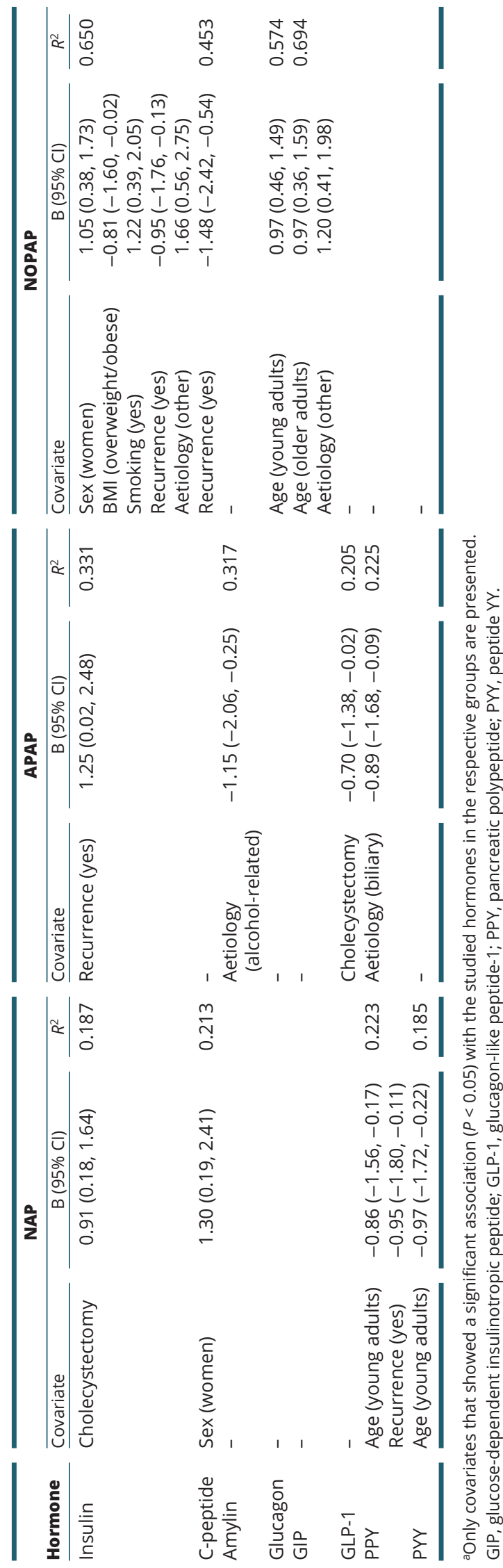

This work is licensed under a Creative Commons Attribution-NonCommercial-NoDerivatives 4.0 elnternationad dicense ifica. com at 04/26/2023 05:12:14AM 
of AP. A key strength of our study is that we purposely included a group of AP patients with antecedent prediabetes (defined as HbA1c between 39 and $47 \mathrm{mmol} /$ mol (5.7-6.4\%)) at baseline and who did not develop newonset diabetes during follow-up. Contrary to the NOPAP group, fasting insulin and glucagon were not statistically significantly associated with the APAP group. This means that the two hormones are positioned well to predict incident, not prevalent, prediabetes in people with a history of AP. Further, a ROC curve analysis showed that insulin and glucagon combined had an AUC (95\% CI) of $0.74(0.60,0.87)$ in predicting NOPAP. This suggests that the two hormones are accurate enough to consider their use in a routine clinical settings (following external validation of our findings) (50). That is why we calculated cut-off thresholds for insulin and glucagon. It is argued that the most clinically useful accuracy metric in the context of predicting NOPAP is negative predictive value (NPV) - the proportion of individuals without the disease (i.e. NOPAP) identified correctly (23). In the present study, the cut-off value of $175 \mathrm{pmol} / \mathrm{L}$ for insulin yielded an NPV of $83 \%$. This means that more than four out of five normoglycaemic AP patients with baseline insulin values $<175 \mathrm{pmol} / \mathrm{L}$ will be correctly identified as those who will not develop NOPAP. An important practical point is that, although the above cut-off value for insulin was derived empirically, it is very similar to previously reported diagnostic thresholds for hyperinsulinaemia (25), indicating that diagnosing hyperinsulinaemia in a normoglycaemic AP patient heralds the future risk of NOPAP. Glucagon yielded a predictive accuracy similar to the one of insulin (NPV of $79 \%)$. Specifically, four out of five normoglycaemic AP patients with baseline glucagon values $<21.4 \mathrm{ng} / \mathrm{L}$ will be correctly identified as those who will not develop NOPAP. The practical application of the above findings is that, once externally validated, insulin and glucagon measurements can be adopted for use in routine clinical practice, enabling health care professionals to triage AP patients according to the risk of future blood glucose derangements and to offer apposite strategies to prevent NOPAP and its associated metabolic abnormalities. It is also worth noting that, although pancreatic polypeptide and peptide YY did not show a statistically significant association with the NOPAP group, the ROC curves for these hormones were not dissimilar from the ROC curves for glucagon (Fig. 1). While our findings did not provide conclusive evidence on the role of pancreatic polypeptide and peptide $\mathrm{YY}$ as predictors of NOPAP, evidence from earlier cross-sectional studies suggests that the gut-brain axis plays a functional role in post-pancreatitis diabetes mellitus (31, 51). Additional research in larger prospective cohorts is required to investigate the role of these hormones in NOPAP.

Several limitations of the study need to be acknowledged. First, the study sample size was relatively small. Yet, significant findings in the NOPAP group suggest that the effect size of the associations of insulin and glucagon is large. At the same time, it is possible that the effect size of the associations between some of the other hormones (e.g. pancreatic polypeptide and peptide YY) and the NOPAP group might have not been large enough to be detected in the present study. Further research is warranted to investigate the above associations in sufficiently powered large-scale studies. Second, one could argue that pancreatitis-related characteristics (e.g. severity of AP) might have affected the studied associations. However, by design, we only included participants with non-necrotising AP. Third, we excluded participants who progressed to newonset diabetes during follow-up. This was done on purpose to ensure that participants were in the early stages of their disease progression and the associated (patho)physiological changes were relatively homogeneous. The present study sets the stage for investigating changes in pancreatic and gut hormones as predictors of new-onset diabetes after AP. Last, all laboratory measurements were done in the fasted state only. This is because the study was designed keeping in mind the practicality of its findings to be implemented in routine clinical practice. However, it is appreciated that deeper insights into the pathogenesis of blood glucose derangements in the post-pancreatitis setting will be gained in studies that employ oral glucose tolerance test or euglycaemic-hyperinsulinaemic clamp test.

In conclusion, elevated fasting levels of insulin and glucagon in normoglycaemic individuals with non-necrotising $\mathrm{AP}$ at baseline portend a heightened risk for NOPAP. The specific thresholds for insulin and glucagon reported in the present study pave the way for operationalising the measurements of plasma insulin and glucagon in routine clinical practice with a view to identifying AP patients who are at high risk of future derangements of glucose metabolism.

\section{Declaration of interest}

The authors declare that there is no conflict of interest that could be perceived as prejudicing the impartiality of the research reported.

\section{Funding}

COSMOS is supported, in part, by the Royal Society of New Zealand (Rutherford Discovery Fellowship to Professor Max Petrov), which played no role in the study design, collection, analysis, or interpretation of data, or writing of the manuscript. 


\section{Author contribution statement}

Study concept and design: M S P. Acquisition of data: S H B, W K, J K. Analysis and interpretation of data: $\mathrm{S} \mathrm{H} \mathrm{B}$. Drafting of manuscript: $\mathrm{S} \mathrm{H} \mathrm{B.}$ Critical revision of the manuscript: W K, J K, and M S P. All authors approved the final version of the manuscript.

\section{Acknowledgements}

This study was part of the Clinical and epidemiOlogical inveStigations in Metabolism, nutrition, and pancreatic diseases (COSMOS) programme.

\section{References}

1 Petrov MS. Diabetes of the exocrine pancreas: American Diabetes Association-compliant lexicon. Pancreatology 201717 523-526. (https://doi.org/10.1016/j.pan.2017.06.007)

2 Petrov MS. DIAGNOSIS OF ENDOCRINE DISEASE: Post-pancreatitis diabetes mellitus: prime time for secondary disease. European Journal of Endocrinology 2021184 R137-R149. (https://doi.org/10.1530/EJE-200468)

3 Cho J, Scragg R \& Petrov MS. Risk of mortality and hospitalization after post-pancreatitis diabetes mellitus vs type 2 diabetes mellitus: a population-based matched cohort study. American Journal of Gastroenterology 2019114 804-812. (https://doi.org/10.14309/ ajg.0000000000000225)

4 Cho J \& Petrov MS. Pancreatitis, pancreatic cancer, and their metabolic sequelae: projected burden to 2050. Clinical and Translational Gastroenterology 202011 e00251. (https://doi. org/10.14309/ctg.0000000000000251)

5 Das SL, Singh PP, Phillips AR, Murphy R, Windsor JA \& Petrov MS. Newly diagnosed diabetes mellitus after acute pancreatitis: a systematic review and meta-analysis. Gut 201463 818-831. (https:// doi.org/10.1136/gutjnl-2013-305062)

6 Shen HN, Yang CC, Chang YH, Lu CL \& Li CY. Risk of diabetes mellitus after first-attack acute pancreatitis: a national population-based study. American Journal of Gastroenterology 2015110 1698-1706. (https://doi. org/10.1038/ajg.2015.356)

7 Lee YK, Huang MY, Hsu CY \& Su YC. Bidirectional relationship between diabetes and acute pancreatitis: a population-based cohort study in Taiwan. Medicine 201695 e2448. (https://doi.org/10.1097/ MD.0000000000002448)

8 Bharmal SH, Cho J, Alarcon Ramos GC, Ko J, Stuart CE, Modesto AE, Singh RG \& Petrov MS. Trajectories of glycaemia following acute pancreatitis: a prospective longitudinal cohort study with 24 months follow-up. Journal of Gastroenterology 202055 775-788. (https://doi. org/10.1007/s00535-020-01682-y)

9 Tabák AG, Herder C, Rathmann W, Brunner EJ \& Kivimäki M. Prediabetes: a high-risk state for diabetes development. Lancet 2012 379 2279-2290. (https://doi.org/10.1016/S0140-6736(12)60283-9)

10 Zhang X, Gregg EW, Williamson DF, Barker LE, Thomas W, Bullard KM, Imperatore G, Williams DE \& Albright AL. A1C level and future risk of diabetes: a systematic review. Diabetes Care 201033 1665-1673. (https://doi.org/10.2337/dc09-1939)

11 Ligthart S, van Herpt TT, Leening MJ, Kavousi M, Hofman A, Stricker BH, van Hoek M, Sijbrands EJ, Franco OH \& Dehghan A. Lifetime risk of developing impaired glucose metabolism and eventual progression from prediabetes to type 2 diabetes: a prospective cohort study. Lancet: Diabetes and Endocrinology 20164 44-51. (https://doi. org/10.1016/S2213-8587(15)00362-9)

12 Diabetes Prevention Program Research Group. Long-term effects of lifestyle intervention or metformin on diabetes development and microvascular complications over 15-year follow-up: the Diabetes Prevention Program Outcomes Study. Lancet: Diabetes and Endocrinology 20153 866-875. (https://doi.org/10.1016/S2213-8587(15)00291-0)
13 Tuomilehto J, Lindström J, Eriksson JG, Valle TT, Hämäläinen H, Ilanne-Parikka P, Keinänen-Kiukaanniemi S, Laakso M, Louheranta A, Rastas M, et al. Prevention of type 2 diabetes mellitus by changes in lifestyle among subjects with impaired glucose tolerance. New England Journal of Medicine 2001344 1343-1350. (https://doi.org/10.1056/ NEJM200105033441801)

14 Stevens JW, Khunti K, Harvey R, Johnson M, Preston L, Woods HB, Davies M \& Goyder E. Preventing the progression to type 2 diabetes mellitus in adults at high risk: a systematic review and network metaanalysis of lifestyle, pharmacological and surgical interventions. Diabetes Research and Clinical Practice 2015107 320-331. (https://doi. org/10.1016/j.diabres.2015.01.027)

15 Gillies CL, Abrams KR, Lambert PC, Cooper NJ, Sutton AJ, Hsu RT $\&$ Khunti K. Pharmacological and lifestyle interventions to prevent or delay type 2 diabetes in people with impaired glucose tolerance: systematic review and meta-analysis. BMJ 2007334 299. (https://doi. org/10.1136/bmj.39063.689375.55)

16 Xiao AY, Tan ML, Wu LM, Asrani VM, Windsor JA, Yadav D \& Petrov MS. Global incidence and mortality of pancreatic diseases: a systematic review, meta-analysis, and meta-regression of populationbased cohort studies. Lancet: Gastroenterology and Hepatology $2016 \mathbf{1}$ 45-55. (https://doi.org/10.1016/S2468-1253(16)30004-8)

17 Petrov MS. Panorama of mediators in postpancreatitis diabetes mellitus. Current Opinion in Gastroenterology 202036 443-451. (https:// doi.org/10.1097/MOG.0000000000000654)

18 American Diabetes Association. Classification and diagnosis of diabetes: standards of medical care in diabetes - 2020. Diabetes Care 202043 S14-S31. (https://doi.org/10.2337/dc20-S002)

19 Petrov MS \& Basina M. DIAGNOSIS OF ENDOCRINE DISEASE: Diagnosing and classifying diabetes in diseases of the exocrine pancreas. European Journal of Endocrinology 2021184 R151-R163. (https://doi.org/10.1530/EJE-20-0974)

20 Jivanji CJ, Asrani VM, Windsor JA \& Petrov MS. New-onset diabetes after acute and critical illness: a systematic review. Mayo Clinic Proceedings 201792 762-773. (https://doi.org/10.1016/j.mayocp.2016.12.020)

21 Fan J, Upadhye S \& Worster A. Understanding receiver operating characteristic (ROC) curves. CJEM 20068 19-20. (https://doi. org/10.1017/s1481803500013336)

22 Hajian-Tilaki K. Receiver operating characteristic (ROC) curve analysis for medical diagnostic test evaluation. Caspian Journal of Internal Medicine 20134 627-635.

23 Attia J. Diagostic tests: moving beyond sensitivity and specificity: using likelihood ratios to help interpret diagnostic tests. Australian Prescriber 200326 111-113. (https://doi.org/10.18773/ austprescr.2003.082)

24 Derakhshan A, Tohidi M, Arshi B, Khalili D, Azizi F \& Hadaegh F. Relationship of hyperinsulinaemia, insulin resistance and $\beta$-cell dysfunction with incident diabetes and pre-diabetes: the Tehran lipid and glucose study. Diabetic Medicine 201532 24-32. (https://doi. org/10.1111/dme.12560)

25 Dankner R, Chetrit A, Shanik MH, Raz I \& Roth J. Basal state hyperinsulinemia in healthy normoglycemic adults heralds dysglycemia after more than two decades of follow up. Diabetes/ Metabolism Research and Reviews 201228 618-624. (https://doi. org/10.1002/dmrr.2322)

26 Carnethon MR, Palaniappan LP, Burchfiel CM, Brancati FL \& Fortmann SP. Serum insulin, obesity, and the incidence of type 2 diabetes in black and white adults: the atherosclerosis risk in communities study: 1987-1998. Diabetes Care 200225 1358-1364. (https://doi.org/10.2337/diacare.25.8.1358)

27 Hulman A, Simmons RK, Brunner EJ, Witte DR, Færch K, Vistisen D, Ikehara S, Kivimaki M \& Tabák AG. Trajectories of glycaemia, insulin sensitivity and insulin secretion in South Asian and white individuals before diagnosis of type 2 diabetes: a longitudinal analysis from the Whitehall II cohort study. Diabetologia 201760 1252-1260. (https:// doi.org/10.1007/s00125-017-4275-6) https://ec.bioscientifica.com https://doi.org/10.1530/EC-21-0229 (c) 2021 The authors Published by Bioscientifica Ltd
This work is licensed under a Creative Commons Attribution-NonCommercial-NoDerivatives 4.0 enternationab dicense.ifica.com at 04/26/2023 05:12:14AM 
28 Tabák AG, Jokela M, Akbaraly TN, Brunner EJ, Kivimäki M \& Witte DR. Trajectories of glycaemia, insulin sensitivity, and insulin secretion before diagnosis of type 2 diabetes: an analysis from the Whitehall II study. Lancet 2009373 2215-2221. (https://doi.org/10.1016/S01406736(09)60619-X)

29 Faerch K, Vaag A, Holst JJ, Hansen T, Jørgensen T \& Borch-Johnsen K. Natural history of insulin sensitivity and insulin secretion in the progression from normal glucose tolerance to impaired fasting glycemia and impaired glucose tolerance: the Inter99 study. Diabetes Care 200932 439-444. (https://doi.org/10.2337/dc08-1195)

30 Petrov MS \& Yadav D. Global epidemiology and holistic prevention of pancreatitis. Nature Reviews: Gastroenterology and Hepatology 201916 175-184. (https://doi.org/10.1038/s41575-018-0087-5)

31 Pendharkar SA, Asrani VM, Xiao AY, Yoon HD, Murphy R, Windsor JA $\&$ Petrov MS. Relationship between pancreatic hormones and glucose metabolism: a cross-sectional study in patients after acute pancreatitis. American Journal of Physiology: Gastrointestinal and Liver Physiology 2016311 G50-G58. (https://doi.org/10.1152/ ajpgi.00074.2016)

32 Bharmal SH, Pendharkar SA, Singh RG, Goodarzi MO, Pandol SJ \& Petrov MS. Relationship between circulating levels of pancreatic proteolytic enzymes and pancreatic hormones. Pancreatology 201717 876-883. (https://doi.org/10.1016/j.pan.2017.09.007)

33 Malecka-Panas E, Gasiorowska A, Kropiwnicka A, Zlobinska A \& Drzewoski J. Endocrine pancreatic function in patients after acute pancreatitis. Hepatogastroenterology 200249 1707-1712.

34 Andersson B, Pendse ML \& Andersson R. Pancreatic function, quality of life and costs at long-term follow-up after acute pancreatitis. World Journal of Gastroenterology 201016 4944-4951. (https://doi. org/10.3748/wjg.v16.i39.4944)

35 Del Prato S, Leonetti F, Simonson DC, Sheehan P, Matsuda M \& DeFronzo RA. Effect of sustained physiologic hyperinsulinaemia and hyperglycaemia on insulin secretion and insulin sensitivity in man. Diabetologia 199437 1025-1035. (https://doi.org/10.1007/ BF00400466)

36 Ferrannini E, Natali A, Bell P, Cavallo-Perin P, Lalic N \& Mingrone G. Insulin resistance and hypersecretion in obesity. European Group for the Study of Insulin Resistance (EGIR). Journal of Clinical Investigation 1997100 1166-1173. (https://doi.org/10.1172/JCI119628)

37 Jeanrenaud B. Central nervous system and peripheral abnormalities: clues to the understanding of obesity and NIDDM. Diabetologia 1994 37 (Supplement 2) S170-S178. (https://doi.org/10.1007/BF00400841)

38 Parker VE, Savage DB, O’Rahilly S \& Semple RK. Mechanistic insights into insulin resistance in the genetic era. Diabetic Medicine 201128 1476-1486. (https://doi.org/10.1111/j.1464-5491.2011.03463.x)

39 Semple RK. EJE PRIZE 2015: how does insulin resistance arise, and how does it cause disease? Human genetic lessons. European Journal of Endocrinology 2016174 R209-R223. (https://doi.org/10.1530/EJE-15-1131)
40 Bharmal SH, Pendharkar S, Singh RG, Cho J \& Petrov MS. Glucose counter-regulation after acute pancreatitis. Pancreas 201948 670-681. (https://doi.org/10.1097/MPA.0000000000001318)

41 Pendharkar SA, Singh RG, Cervantes A, DeSouza SV, Bharmal SH \& Petrov MS. Gut hormone responses to mixed meal test in new-onset prediabetes/diabetes after acute pancreatitis. Hormone and Metabolic Research 201951 191-199. (https://doi.org/10.1055/a-0802-9569)

42 Færch K, Vistisen D, Pacini G, Torekov SS, Johansen NB, Witte DR, Jonsson A, Pedersen O, Hansen T, Lauritzen T, et al. Insulin resistance is accompanied by increased fasting glucagon and delayed glucagon suppression in individuals with normal and impaired glucose regulation. Diabetes 201665 3473-3481. (https://doi.org/10.2337/ db16-0240)

43 Baron AD, Schaeffer L, Shragg P \& Kolterman OG. Role of hyperglucagonemia in maintenance of increased rates of hepatic glucose output in type II diabetics. Diabetes 198736 274-283. (https:// doi.org/10.2337/diab.36.3.274)

44 Ichikawa R, Takano K, Fujimoto K, Motomiya T, Kobayashi M, Kitamura T \& Shichiri M. Basal glucagon hypersecretion and response to oral glucose load in prediabetes and mild type 2 diabetes. Endocrine Journal 201966 663-675. (https://doi.org/10.1507/endocrj.EJ18-0372)

45 Ahrén B. Glucagon secretion in relation to insulin sensitivity in healthy subjects. Diabetologia 200649 117-122. (https://doi. org/10.1007/s00125-005-0056-8)

46 Robinson LE \& van Soeren MH. Insulin resistance and hyperglycemia in critical illness: role of insulin in glycemic control. AACN Clinical Issues 200415 45-62. (https://doi.org/10.1097/00044067-20040100000004)

47 Woodmansey C, McGovern AP, McCullough KA, Whyte MB, Munro NM, Correa AC, Gatenby PAC, Jones SA \& de Lusignan S. Incidence, demographics, and clinical characteristics of diabetes of the exocrine pancreas (type 3c): a retrospective cohort study. Diabetes Care 201740 1486-1493. (https://doi.org/10.2337/dc17-0542)

48 Bendor CD, Bardugo A, Zucker I, Cukierman-Yaffe T, Lutski M, Derazne E, Shohat T, Mosenzon O, Tzur D, Sapir A, et al. Childhood pancreatitis and risk for incident diabetes in adulthood. Diabetes Care 202043 145-151. (https://doi.org/10.2337/dc19-1562)

49 Cho J, Pandol SJ \& Petrov MS. Risk of cause-specific death, its sex and age differences, and life expectancy in post-pancreatitis diabetes mellitus. Acta Diabetologica 202158 797-807. (https://doi.org/10.1007/ s00592-021-01683-0)

50 Petrov MS. Predicting the severity of acute pancreatitis: choose the right horse before hitching the cart. Digestive Diseases and Sciences 2011 56 3402-3404. (https://doi.org/10.1007/s10620-011-1924-3)

51 Pendharkar SA, Asrani VM, Murphy R, Cutfield R, Windsor JA \& Petrov MS. The role of gut-brain axis in regulating glucose metabolism after acute pancreatitis. Clinical and Translational Gastroenterology 2017 8 e210. (https://doi.org/10.1038/ctg.2016.63)

Received in final form 14 May 2021

Accepted 3 June 2021

Accepted Manuscript published online 7 June 2021 https://ec.bioscientifica.com https://doi.org/10.1530/EC-21-0229 (c) 2021 The authors Published by Bioscientifica Ltd
This work is licensed under a Creative Commons Attribution-NonCommercial-NoDerivatives 4.0 International License.ifica com at $04 / 26 / 2023 \quad 05: 12: 14 \mathrm{Am}$ 